\title{
CULTURA ESCOLAR E INCLUSÃO DE ALUNOS SURDOS EM QUESTÃO: BREVE REFLEXÃO TEÓRICA
}

\author{
The school culture and the deaf student inclusion in question: short reflection and \\ theoretic notes
}

Cultura escolar e inclusión de alumnos surdos en cuestión: breve reflexión teórica

Grazielly Vilhalva Silva do Nascimento ${ }^{1}$

Reinaldo dos Santos ${ }^{2}$

\begin{abstract}
Resumo
Os princípios de inclusão escolar advogam uma educação para todos independentes de sua raça, cor, religião, classe social e deficiência, no entanto, para além da elaboração de políticas públicas que garantam o acesso e permanência desse alunado na escola, emerge como uma das premissas básicas para o sucesso das ações inclusivas, a necessidade da reestruturação da instituição escolar no que se refere às práticas e formas de transmitir ou "reproduzir" o ensino. O fazer docente resultante de valores e crenças assimilados ao longo de anos, concebe o ensino sob a visão da existência de um aluno padrão, utilizando práticas homogêneas de ensino que não considera e nem valoriza a diversidade. Assim, neste artigo, temos como objetivo realizar algumas reflexões teóricas de forma a compreender as relações entre cultura, inclusão de aluno surdo e a escola por meio de um estudo bibliográfico embasado em autores que discutem a educação de surdos e autores que discutem a cultura escolar. A compreensão de cultura escolar aqui é entendida como processo/produto histórico, mutável e instável à medida que é produzida na tensão entre grupos e nas diferentes expectativas sobre a função social da escola, que muda de acordo com cada espaço de tempo da história.
\end{abstract}

PALAVRAS-CHAVE: Cultura Escolar. Inclusão escolar. Aluno surdo

\begin{abstract}
The present text shows a discussion about the school culture and the deaf students inclusion in common classes of the regular teaching network as well as the teaching practice dedicated to them, in a trying to understand how these relations occurs inside the classrooms. The school inclusion principles advocate an education for all, independent of the race, color, religion, social class and deficiency, however beyond of the elaboration of public policies that assures the access and permanence of this student at school, rises the needing of the restructuring of the educational institution in what refers to the practices and ways of transmitting or "reproducing" the teaching, this restructuring would be then one of the basic previous to the success of the inclusion actions. The docent perform resulted by values and trusts assimilated over the years, designs the teaching under the vision of the existence of a standard student, using homogeny teaching practices that doesn't consider or values the diversity. This research's objective is to do some theoretical reflections tending to understand the relations between culture, deaf student inclusion and the school by a bibliographic based on authors that discuss Deaf Education and authors that discuss the academic culture. The School Culture comprehension here is understood as historic process/product, changeable and unstable as it's formed in the tension between groups and in the

\footnotetext{
${ }^{1}$ Professora Assistente II da Faculdade de Educação da Universidade Federal da Grande Dourados-UFGD. Mestre em Educação e Doutoranda em Educação pelo Programa de Pós-Graduação em Educação da UFGD. E-mail: grazivsn@uol.com.br.

${ }^{2}$ Professor Associado I da Universidade Federal da Grande Dourados, docente do Mestrado e Doutorado em Educação. Bolsista de Desenvolvimento Tecnológico Industrial C - CNPQ.
} 
different expectations about the social obligation of the school, that changes according to each space and time of history.

KEYWORDS: School Culture. School inclusion. Deaf student

\begin{abstract}
Resumen
Los principios de inclusión escolar abogan una educación para todos independientes de su raza, color, religión, clase social y discapacidad, sin embargo, además de la elaboración de políticas públicas que garanticen el acceso y permanencia de ese alumnado en la escuela, emerge como una De las premisas básicas para el éxito de las acciones inclusivas, la necesidad de la reestructuración de la institución escolar en lo que se refiere a las prácticas y formas de transmitir o "reproducir" la enseñanza. El hacer docente resultante de valores y creencias asimilados a lo largo de años, concibe la enseñanza bajo la visión de la existencia de un alumno estándar, utilizando prácticas homogéneas de enseñanza que no considera ni valoriza la diversidad. Así, en este artículo, tenemos como objetivo realizar algunas reflexiones teóricas para comprender las relaciones entre cultura, inclusión de alumno sordo y la escuela por medio de un estudio bibliográfico basado en autores que discuten la educación de sordos y autores que discuten la cultura escolar. La comprensión de la cultura escolar aquí se entiende como proceso / producto histórico, mutable e inestable a medida que se produce en la tensión entre grupos y en las diferentes expectativas sobre la función social de la escuela, que cambia de acuerdo con cada espacio de tiempo de la historia.
\end{abstract}

Palabras clave: Cultura Escolar. Inclusión escolar. Estudiante Sordo

\title{
INTRODUÇÃO
}

Este ensaio teórico advém de reflexões acerca da inclusão de alunos surdos nas escolas comuns. Essas inquietações surgem a princípio de experiências empíricas no que concerne a prática profissional em dois contextos distintos de educação para surdos: a escola comum e a escola dita bilíngue para surdos que culminaram em uma inflexão acerca das práticas docentes e do cotidiano escolar em ambos os contextos citados. Essa inflexão inicial mostrou a necessidade da busca por leituras e análises de fontes primárias como os documentos legais que versam sobre a educação de surdos no Brasil, a proposta de inclusão escolar e também de leituras e estudos temáticos que contemplassem ou explicassem o fenômeno da inclusão escolar. Ao se debruçar sobre estas leituras e análises percebeu-se também a necessidade de uma discussão que abarcasse a questão da cultura escolar como uma forma de trazer luz aos vários nós encontrados na educação de surdos, especialmente quando discutimos a questão da inclusão escolar destes alunos e os resultados para além de acesso e permanência na escola comum, e sim daqueles relacionados aos ganhos acadêmicos na trajetória escolar destes alunos.

A partir da reflexão sobre a diferença linguísticas existente entre surdos e ouvintes e os problemas enfrentados por esse alunado concernente ao desenvolvimento da linguagem e aquisição da Libras - Língua Brasileira de Sinais somado aos demais problemas enfrentados pelas práticas de inclusão escolar já conhecidos por todos aqueles que de alguma maneira discutem e estudam sobre a inclusão escolar, foram levantadas algumas questões:

Como promover a aprendizagem significativa desses alunos?

Os professores compreendem o que vem a ser ensino bilíngue para surdos, ensino de português como segunda língua e o papel do intérprete de Libras na sala de aula? 
Existe uma imposição "ouvintista" 3 " de forma a colonizar os alunos surdos presentes emclasses comuns do ensino regular?

$\mathrm{Na}$ contemporaneidade, termos como: inclusão, educação especial, aluno com necessidades educacionais especiais ou e necessidades específicas, educação bilíngue para surdos, Libras como L1 (primeira língua) e Língua Portuguesa na modalidade escrita como L2 (segunda língua), são muito comuns e recorrentes, nesse cenário, situa-se a educação de surdos configurada no discurso da inclusão e da educação bilíngue respaldadas pela ideia do respeito e até mesmo da valorizaçãoda diferença, todavia, percebe-se que estes termos são referendados de forma trivial e simplória, quando na verdade demandam da escola, dos docentes e da comunidade escolar uma modificação radical para que estes alunos obtenham aprendizagens significativas, uma vez que na prática, pouco se conhece ou quer se conhecer de fato sobre este aluno surdo, suas particularidades, sua língua e as condições necessárias para o seu desenvolvimento linguístico e acadêmico em paridade com os alunos ouvintes.

A prática de inclusão e escolarização de alunos surdos pautados na proposta de educação bilíngue ${ }^{4}$, bem como no início da construção de uma política linguística e cultural adequada a esses alunos vem acontecendo no cenário nacional amparados em documentos como a LDBEN - Lei $n^{\circ}$ 9.394/1996, Resolução CNE/CEB nº 2/2002, Lei de Libras - Lei $n^{\circ} 10.436 / 2002$, Decreto $n^{\circ} 5.626 / 2005$, a Política Nacional de Educação Especial na Perspectiva da Educação Inclusiva (MEC, 2008) e por fim, o atual Plano Nacional de Educação (PNE 2014-2024) aprovado pela Lei ${ }^{\circ} 13.005$ de 25 de junho de 2014 e o estatuto da pessoa com deficiência sancionada pela lei $n^{\circ} 13.146 / 2015$ cujas aprovações representam um marco para a efetivação da educação bilíngue para surdos em escolas ou classes bilíngues. Estes dois documentos passam a nortear as formas de atendimento educacional disponível aos surdos brasileiros.

Tais documentos entre outros, visam garantir o acesso e permanência desse alunado às escolas comuns da rede regular de ensino apontando também formas adequadas de atendimentos aos alunos surdos. No entanto, embora se reconheça o importante papel da elaboração e implementação dessas políticas públicas de inclusão, é incontestável que essas nem sempre repercutem no sentido de modificar as práticas de ensino uniformes e homogeneizadoras até então estabelecidas no cotidiano escolar.

\section{A Educação de Surdos: realidades, necessidades e desafios para a escola comum}

Bueno (2008. P. 43) afirma que "a inclusão escolar surge como a nova missão da escola, no sentido atribuído por Hargreaves (1996, p. 8 e 9)”, essa nova missão cria uma tensão no cotidiano escolar, pois desestrutura a forma instituída de ensino-aprendizagem, a

\footnotetext{
${ }^{3}$ O Ouvintismo de acordo com Skliar, "é um conjunto de representações dos ouvintes, a partir do qual o surdo está obrigado a olhar-se e narrar-se como se fosse ouvinte". (1998, p 15). Nessa perspectiva de análise o ouvintismo estaria também presente nas práticas educacionais com alunos surdos onde os ouvintes determinam e decidem qual a melhor forma do surdo aprender, visto que nesta perspectiva a surdez é vista como marca de inferioridade e a pessoa ouvinte "sabe mais" que a pessoa surda.

${ }^{4}$ Entende-se por educação bilíngue para surdos a proposta educacional onde a Libras - Língua Brasileira de Sinais é tratada como a primeira língua dentro do processo de ensino para surdos e a Língua Portuguesa na modalidade escrita constitui segunda língua. (Cf. Brasil, 2005). A abordagem educacional por meio do bilinguismo visa capacitar a pessoa surda para a utilização de duas línguas no cotidiano escolar e na vida social, quais sejam: a língua de sinais e a língua da comunidade ouvinte. Estudos têm demonstrado que esta abordagem corresponde melhor às necessidades do aluno com surdez, em virtude de respeitar a língua natural e construir um ambiente propício para a sua aprendizagem escolar. (Cf. MEC, 2010).
} 
escola passa a ter o dever de oportunizar o desenvolvimento das potencialidades dos alunos com necessidades educativas especiais através do atendimento as suas necessidades específicas.

No caso dos alunos surdos, a principal diferença evidenciada é a de cunho linguístico, já que estes se comunicam pela Libras - Língua Brasileira de Sinais. A Declaração de Salamanca de 1994, as Diretrizes Nacionais para a Educação Especial na Educação Inclusiva (CNE/CEB, 2001), Resolução $\mathrm{n}^{\circ} 2$ de 2001, Lei de Libras $\mathrm{n}^{\circ}$ 10.436/2002, o Decreto $n^{05} 5.626 / 2005$, a Política Nacional de Educação Especial na perspectiva da Educação Inclusiva - MEC 2008 e o atual Plano Nacional de Educação (PNE 2014-2024) aprovado pela Lei $\mathrm{n}^{\circ} 13.005$ de 25 de junho de 2014 entre outros documentos já citados explicitam a necessidade dos alunos surdos de serem ensinados na sua língua, no caso a Libras. Contudo, as necessidades dos alunos surdos vão além da utilização da Língua de Sinais, como afirma Perlin apud Strobel (2006), "a educação de surdo tem de ser a educação específica com códigos da cultura surda".

Dorziat afirma que, sem dúvida, a nova visão de surdez teve a valorização da Libras como um aspecto importante e relevante, porque esse reconhecimento permitiu trazer à discussão "a possibilidade de se adotarem processos humanizadores na educação das pessoas surdas" (DORZIAT 2009), isso porque, de acordo com esta mesma autora, historicamente, os surdos vinham sofrendo as consequências de processos educacionais, que se caracterizavam pela secundarizarão do ensino e suas implicações e pela preocupação extremada com o fator biológico, clínico, que submetia essas pessoas a treinos sistemáticos da linguagem oral e levava a escola a adotar a função eminentemente terapêutica

Esse passado recente na educação de surdos deixou marcas ainda latentes, a disseminação da "incapacidade do surdo para aprender" ressaltada pelo fracasso escolar destes sujeitos que ao invés de atestarem o fracasso da escola em ensiná-los acabou por estigmatiza-los . Nessa caminhada histórica e social, constatamos as marcas depreciativas que socialmente a surdez contém. Em se tratando das concepções sociais acerca da surdez Botelho (2005, p.23) afirma que,

[...] No caso dos surdos, a menos valia se acentua com uma concepção de surdez como marca depreciativa, por internalização de estigma e de preconceito. Tal percepção produz sentimentos de incapacidade, e intensifica os temores em relação a como somos vistos pelos outros, criados pelas formações imaginárias.

Partindo desse pressuposto, entendemos que para alcançar o sucesso nas práticas de ensino com esses educandos, a metodologia de ensino empregada, os procedimentos didáticos, bem como os recursos de ensino utilizados devem ser repensados pelo professor e demais profissionais da escola que busca trabalhar de uma forma efetivamente inclusiva.

Dessa forma entra em xeque valores, conceitos e pré-conceitos relacionados com a cultura escolar até então estabelecida. Jesus (2008) aponta que o discurso do não "estar preparado" e "não saber" lidar com alunos deficientes tornou-se um discurso institucionalizado acerca da inclusão escolar. Chervel apud Silva $(2008$, p. 71) esclarece que, "a escola fornece à sociedade uma cultura constituída de duas partes: os programas oficiais, que explicitam sua finalidade educativa e os resultados efetivos da ação da escola, os quais, no entanto, não estão inscritos nessa finalidade". 
O referido discurso não afinado com atual política de inclusão escolar vigente no país resulta de um processo histórico. A escola que tem em seu histórico, educar para a obediência, para ordem, para a acomodação e para a aceitação do mundo vivente, quando se depara com o novo, o diferente, a reação é de não aceitação, em se tratando da surdez o que encontramos historicamente é uma educação voltada para a normalização, educar para a fala oral e para a leitura labial. Assim, o ensino da fala ocupa um papel central no processo de ensino aprendizagem da criança surda, desconsiderando sua língua natural e toda uma conjuntura inerente à surdez.

A pessoa surda tem uma língua própria por natureza, pois é a língua que a criança surda tem predisposição natural para aprender, segundo Quadros e Karnopp (2004, p.30) as línguas de sinais são consideradas pela linguística como um sistema linguístico legitimo e não como um problema do surdo ou como uma patologia da linguagem. Em 1960, Willian Stokoe, linguista americano, por meio de estudos pioneiros da ASL - Língua de Sinais Americana apresentou dados descritivos desta língua que comprovava que a ASL atendia a todos os critérios linguísticos de uma língua genuína, no léxico, na sintaxe, e na capacidade de gerar uma quantidade infinita de sentenças. A língua de sinais é a primeira língua da criança surda e por esta razão a Língua Portuguesa é a segunda língua que deveria ser ensinada dentro do contexto escolar na modalidade escrita para estas crianças.

Um dos aspectos mais complexos dessa necessidade específica dos alunos surdos consiste nas metodologias de ensino empregadas dentro de sala de aula, especialmente no processo de alfabetização, isso porque as metodologias de ensino pautam-se na premissa de alfabetização de primeira língua, e ainda que considere como ensino de segunda língua, quase sempre a estratégia de ensino é voltada para pessoas com aporte auditivo, consequentemente fonético. A Língua Portuguesa é uma língua oral e fonética ao passo que a Libras é uma língua de natureza visuoespacial e a pessoa surda não tem o aporte fonético para a aquisição da Língua Portuguesa na modalidade escrita, ou seja, há outra demanda metodológica de ensino-aprendizagem, ou indo na raiz da questão, há uma demanda de métodos diferenciados de alfabetização que leve em conta estas características.

Para melhor contextualizar essa problemática, faz-se necessário ilustrar a realidade da maioria das crianças surdas, de como chegam à escola linguisticamente falando, de como são alfabetizadas e como adquirem não uma, mas duas línguas ao mesmo tempo, essa ilustração permitirá uma visualização desse quadro complexo. Em geral, as crianças surdas possuem pais ouvintes não falantes da Libras e que possuem naturalmente, ampla expectativa de que seus filhos venham a desenvolver e adquirir a língua oral,logo, toda a concentração de esforços familiar nos anos iniciais desta criança consistena busca da aquisição da língua oral. Essa realidade faz com que em geral, estas crianças cheguem à escola sem uma base linguística consistente, ou ainda, com lacunas no desenvolvimento linguístico, chegam às séries inicias do Ensino Fundamental sem a língua de sinais e sem a língua oral (Cf. Quadros, 2006, Góes e Tartucci, 2012). É na escola então, que esta criança terá seus primeiros contato com a Libras, seu modelo linguístico será o seu intérprete educacional, com fluência e formação linguística em Libras também frágeis(Cf. Lacerda, 2012), e, ao mesmo tempo em que se inicia o seu processo de aquisição da Libras, sua língua natural,inicia-se também sua alfabetização em Língua Portuguesa, língua com a qual, de forma bem diferente das crianças ouvintes que ingressam na escola com amplo conhecimento, vocabulários e experiências linguísticas, não possuem experiência linguística, ou experiência linguística incipiente, quando comparadas às crianças ouvintes. 
A ilustração apontada no parágrafo anterior serve para elucidar a realidade destas crianças, e para que se visualize a complexidade do processo de ensino-aprendizagem deste alunado, uma vez que se, crianças ouvintes com fluência linguística em Língua Portuguesa na modalidade oral e com aporte auditivo para a aprendizagem de uma língua escrita de natureza fonética apresentam dificuldades de aprendizagem, especialmente no que tange a alfabetização, a complexidade que envolve a alfabetização da criança surda em Língua Portuguesa como segunda língua é exponencialmente maior e desafiadora.

A diferença entre os indivíduos existe, é fato, e não pode ser negada, mas se for respeitada pela sociedade e vista pela escola como expressão da diversidade, servirá de parâmetro para tornar socialmente melhor as relações, ao invés de levar ao isolamento, ou ao fracasso escolar e fracasso como cidadão. Pimenta (2001, p. 24 apud Salles et al. p.39) expressa que, a surdez deve ser reconhecida como apenas mais um aspecto das infinitas possibilidades da diversidade humana, pois ser surdo não é melhor ou pior do que ser ouvinte é apenas diferente. Nesse sentido, Perlin e Strobel (2006, p.28 e 29) afirmam que "a educação de surdos nesta teorização cultural contemporânea sobre a identidade e a diferença parece ser o caminho, entramos em momentos que primam pela defesa cultural: a educação na diferença na mediação intercultural”. Assim para elas,

Esta modalidade oferece fundamento para a educação dos surdos a partir de uma visão em uma outra filosofia invariável hoje. Em que a educação dá-se no momento em que o surdo é colocado em contato com sua diferença para que aconteça a subjetivação e as trocas culturais. A modalidade da 'diferença' se fundamenta na subjetivação cultural. Ele surge no momento que os surdos atingem sua identidade, através da diferença cultural, surge no espaço pós-colonial. Neste espaço não mais há a sujeição ao que é do ouvinte, não ocorre mais a hibridação, ocorre a aprendizagem nativa própria do surdo. (...) para Fleuri (2000), o que é inovador em educação é o iniciar a focalizar momentos e processos produzidos face às diferenças culturais. Nesta direção, a perspectiva intercultural pode estimular os surdos a enfatizar os aspectos de identidade/alteridade com estímulos para desenvolver a capacidade de reflexão sobre a diferença cultural, ao lado da possibilidade solidária de interação com outros grupos culturais. (PERLIN E STROBEL, 2006. p.30).

A escola deveria considerar esta diversidade apropriando-se de recursos e estratégias didático-metodológicas que permitam o desenvolvimento das habilidades e competências de seu alunado. Na educação de surdos deve haver a primazia do uso das Libras - Língua Brasileira de Sinais, reconhecida como língua e parte fundamental no processo de ensino, isso porque embora oficialmente já seja reconhecida como tal, na pratica ainda há resquícios de filosofias anteriores com concepções distorcidas acerca da língua de sinais. A língua brasileira de sinais é uma língua visual-espacial-articulada através das mãos, das expressões faciais e do corpo, constitui uma língua natural usada pela comunidade surda brasileira. Quadros e Karnopp (2004, p.47) enfatizam que as línguas de sinais são denominadas línguas de modalidade gestual porque as informações linguísticas são recebidas pelos olhos e transmitidas pelas mãos. Nascimento (2013, p. 123) aponta que, ao invés de elaborar estratégias para a superação das dificuldades de leitura e escrita dos alunos surdos, as práticas escolares tendem para a acomodação e aceitação dessa dificuldade como uma limitação do sujeito, algo aceito como dado, que 
não pode ser modificado. Essa realidade faz com que poucos desenvolvam a habilidade de leitura e escrita e avancem pelas séries escolares com habilidade de leitura e escrita incompatíveis com o nível de ensino, isso até o momento em que esta situação passe a não mais se sustentar devido aos níveis de exigências cada vez maior o que finalmente acaba por "expulsar" estes alunos da vida escolar.

\section{O aluno surdo e a cultura escolar: caminhos e descaminhos da inclusão}

Esse movimento exige uma mudança nas formas de produzir e transmitir o conhecimento pela escola. Mudança, que devemos reconhecer, ocorrerá de forma dificultosa e lenta, haja vista que estes moldes de ensino estão enraizados na escola desde a criação das escolas para as massas populacionais, no início da revolução industrial, período de transição entre o feudalismo e o capitalismo industrial. $\mathrm{O}$ modelo de funcionamento da escola desde então se assemelha em muitos aspectos ao modelo de funcionamento fabril ou industrial. . Nesse sentido D'antino (1997) afirma,

Podemos destacar que a plena inclusão não se consolidará sob os pilares educacionais de uma sociedade capitalista, competitiva, a qual preconiza o bom desempenho, a produtividade, ovigor, a beleza, entre outras características, que talvez estejam distantes da realidade de alguns alunos ditos "especiais". (Cf. D' ANTINO, 1997).

“O surdo encontra-se em conflito dada a política de inclusão no ensino regular, pois este não é atendido por uma pedagogia da diferença, ou seja, uma prática cultural que permita ao surdo construir sua subjetividade como diferente do ouvinte". (Campos, 2014. p.41)

A mudança nessa estrutura e consequentemente na cultura escolar, ao menos hipoteticamente levariam a uma nova forma de concepção sobre o aluno com necessidade educacional especial e sobre a vigente prática excludente de inclusão escolar. Mendes (2008, p.116) explica que a prática é resultado da cultura objetivada e da experiência compartilhada, nossas ações são frutos dessas objetivações da cultura, assim, essa compreensão torna-se também, segundo a autora, trilhas, caminhos e sulcos que guiam as ações futuras.

O conceito de cultura escolar possui, como Aponta Vidal (2005, p. 23 e 24) vários significados concorrentes, no entanto trazemos aqui a compreensão de Julia descrita no texto da autora,

Para ser breve, poder-se ias descrever a cultura escolar como um conjunto de normas que definem conhecimentos a ensinar e condutas a inculcar, e um conjunto de práticas que permitem a transmissão desses conhecimentos, e a incorporação desses conhecimentos; normas e práticas coordenadas a finalidades que podem variar segundo as épocas (finalidades religiosas, sociopolíticas ou simplesmente de socialização) Normas e práticas que não podem ser analisadas sem se levar em conta o corpo profissional dos agentes que são chamados a obedecer essas ordens e portanto, a utilizar os discursos pedagógicos encarregados de facilitar sua aplicação, a saber os professores primários e os demais professores. Mas para além dos limites da escola, pode-se buscar identificar em um sentido mais amplo, modos de pensar e agir largamente difundidos no interior de 
nossas sociedades, modos que não concebem a aquisição de conhecimentos e de habilidades senão por intermédio dos processos formais de escolarização [...] (JULIA, 2001, p.10-11 apud Vidal 2005, p.24)

A escola que deseja ser inclusiva necessita desvendar essas trilhas, esses caminhos condutores de ações futuras concebidas na perspectiva da inclusão escolar, sulcos que nos façam perceber potenciais na diferença, e conceber novas práticas de ensino que permitam a promoção da aprendizagem de todos os alunos. O sociólogo inglês Hargreaves, em uma entrevista concedida a revista Propuesta Educativa $n^{\circ}$ 27, afirma que,

[...] las escuelas em contextos democráticos necesitan ser comunidades, necesitan ser inclusivas, constituirse em lugares donde los maestros comprenden a sus alumnos y se relacionan com ellos de modo tal que todos accedan al conocimiento, y donde no solo atienden a um tipo de alumno em particular, los mejores o los más inteligentes, sino a todos. (...) Em esse sentido, todos los estudiantes de todas las classe sociales necesítan tene la oportunidad y la expectativa de desarrolar todo tipo de capacidades. Las escuelas tienem que poder enseñar a todo tipode alumnos, no solo a unos pocos, y para eso hay que poder ser muy creativo y flexible. Sin. embargo, lo que vemos es que se opto por la estandarización escolar y esto es exactamente lo opuesto a lo que necesítamos en términos de creatividad y flexibilidad y en términos de comunidad e inclusión. (HARGREAVES, Rev. Propuesta Educativa/27, p.64 e 65)

Barroso apud Dalabrida (2008, p. 266) que afirma serem múltiplas as formas de exclusão exercida pela escola, por exemplo, não deixando entrar os que estão de fora e pondo fora os que estão dentro. A escola exclui incluindo através de uma exclusão sutil, pois oferece o acesso, permite a entrada em seu espaço, porém não estrutura sua prática para promoção da aprendizagem "fazendo que o sentimento de pertencimento, à escola, não atinja os alunos que possuam diferenças no seu potencial educativo".

Não se trata de culpabilizar os professores pelos insucessos de práticas de inclusão e de conceber afirmações como as de que a escola não está preparada para a inclusão escolar desses alunos, nem tampouco simplificar com falas do tipo "é a cultura escolar", com efeito, esse vem sendo o caminho mais fácil para justificar o fracasso ocorrido, entretanto entendemos que outras análises e novas proposições devem ser processadas como meio de não mais afirmar sobre uma escola que não sabe incluir e sobre uma cultura escolar única e imutável, mas proposições que tragam possibilidades efetivas e apontamentos para a prática profícua de uma educação inclusiva.

Patto (2008, p. 34) afirma que "a escola de fato inclusiva é a escola que esclarece, a partir da própria experiência dos dominados" relata que desde o fim da ditadura no Brasil, o sonho de uma escola pública mais igualitária assumiu várias formas promissoras, e que da intenção a realidade o fosso sempre foi enorme. Assim percebe-se que o problema das desigualdades no seio da escola não é novo, e nem uma exclusividade vivida pelos alunos com necessidades educacionais especiais, mas porque isso acontece? Segundo a mesma autora a medicalização de desvios, definidos a partir de um discutível conceito de normalidade, o entendimento da igualdade como produção do uniforme e a formação do professor entendida como aperfeiçoamento, treinamento ou reciclagem além das modas teóricas substituídas e descartadas rapidamente entre outros fatores por ela citados, fizeram 
com que o professor se tornasse um "peão de ensino", com sua morte decretada, tornandose refém de políticas eleitoreiras e descontinuidade técnica administrativa.

Um professor bem preparado, consciente e liberto das condições acima citadas, certamente será capaz de modificar sua prática educativa, não raro escutamos professores, principalmente os que estão atuando a mais tempo, reclamando ou justificando que em sua graduação não tiveram disciplinas voltadas para o atendimento das necessidades específicas dos alunos com necessidades especiais educacionais, nos atuais moldes instituídos.

Assim, a questão não abrange somente casos onde professores rejeitam a inclusão escolar e nada fazem para que ela se efetive, trata-se também de professores conscientes de seu papel de educador, porém, que não sabem o caminho a seguir, desconhecem as ferramentas a serem utilizadas e metodologias viáveis a serem empregadas de acordo com cada necessidade específica de cada aluno alvo da educação especial, que chega a sua sala de aula.

Dessa maneira, recebem os alunos surdos sem saberem como com eles atuar, como coordenar o atendimento ao grupo respeitando as especificidades individuais e coletivas, urge compreender que os professores estão em processo de transformação de uma prática de ensino voltada para o todo, o homogêneo, para a uma prática voltada para as diferenças, o heterogêneo.

A concepção da surdez como sinônimo de incapacidade ainda é latente o que acaba por sustentar práticas excludentes de ensino nas escolas ditas inclusivas. Nasce na escola uma tensão entre o progresso e a permanência, no entanto é nesse espaço tempo de tensão que a cultura escolar se reinventa em uma construção e produção ancorada na dinâmica relacional da escola: diferenças de gênero, geração, etnia, classes e grupos sociais, culturas, relações de poder e hierarquia. Essa reinvenção se caracteriza como "furtividades", no sentido em que define Certeau (1985, p. 3), à medida que consideramos a escola no campo da produção e os alunos como consumidores, "todavia, ao lado do consumidor também há uma produção: ele transforma o espaço que lhe é imposto." Essa relação dos alunos como consumidores não passivos com a escola, pode transformar as ações produzidas pela escola.

\section{CONSIDERAÇÕES FINAIS}

Nesse estudo buscou-se compreender as relações existentes entre cultura, inclusão de aluno surdo e práticas de ensino numa tentativa de compreender o que está por detrás dessas relações. O que as leituras nos apontam é que embora essas relações sejam tensas, são essas tensões que fazem com que as mudanças ocorram. Os estudos das culturas escolares no campo da história da educação mostraram que a cultura escolar não é estável e se modifica à medida que sociedade se modifica, uma influenciando a outra.

Estamos em época de mutação, Certeau (idem, p. 4) explica que a análise do cotidiano se torna mais significativa em uma época de mutação, de trânsito. Compreendese então que a escola em dias de inclusão vive esse momento de passagem, de trânsito. A política de inclusão foi implementada e os alunos surdos passaram a ter seu acesso à escola comum garantido, a questão é analisar e compreender a lógica da ação ou morfologia da 
ação docente: quais têm sido as práticas de ensino no que se refere a Libras e as metodologias de ensino empregadas no atendimento a esses alunos? Será que as necessidades específicas desses alunos tem sido atendidas, as práticas mudaram? A escola comum tem uma nova clientela: os alunos surdos, e todo um aparato legal que norteia como deve ser suas ações, ao pinçar a expressão "I falt savoir avec" do texto de Certeau e aplicando-a ao contexto da inclusão escolar constatamos que os alunos surdos estão presentes, as políticas públicas de inclusão promulgadas por meio de vários documentos legais vêm sendo implementadas, e a escola com suas regras e práticas engessadas precisade resiliência o "saber lidar', "se virar", aprender a trabalharna e para a inclusão, precisa reinventar e ressignificar as suas práticas.

Em Dermatini (2004, p.92), encontramos que "a melhor educação (...) será aquela que mais tiver o sentido da diferença, do pluralismo cultural, do caráter aberto e plural do ser humano" (Santos e Correia, 1993, p 7-10 apud Dermatini 2004). Dermatini explica que as culturas indígenas, culturas negras, e culturas de minorias étnicas e outras culturas foram desenhada no séc. XIX marginalmente e em função de uma cultura dominantes. Diante dessa constatação entende-se que as mudanças ambicionadas, são processos e não se realizarão de forma instantânea.

Filho,(2002, p.34) afirma,

É dessa escola que somos herdeiros, tanto quanto somos herdeiros e construtores da sociedade que nela se insere. É possível reinventá-las? Uma resposta positiva a essa questão é o que tem movido um grande número de estudiosos e professores ainda neste início de século XXI. Tal perspectiva tem perpassado os estudos históricos que, à sua maneira, tem contribuído para tal façanha buscando entender as várias formas de constituição da escola na sociedade brasileira.

Cabe então, aos gestores escolares, técnicos administrativos, corpo docente, e demais membros da comunidade escolar modificar as atuais práticas excludentes de inclusão escolar, o fato de não ser possível modificar essa realidade instantaneamente, não significa fadar-se ao permanente fracasso, e sim que deve haver engajamento para operacionalizar as mudanças necessárias apontadas, estamos em um processo histórico de mudanças políticas, educacionais e culturais muito esperado pelas comunidades surdas.

Podemos vislumbrar a médio e longo prazo a atuação de uma nova geração de professores com formação inicial que contemplem o atendimento adequado aos alunos com necessidades educacionais especiais e por meio de uma escola que será capaz de por em praticas os novos paradigmas estabelecidos sobre esse alunado. A construção de uma escola inclusiva dependerá dos ajustes necessários para a superação dos desafios elencados.

\section{REFERÊNCIAS}

BUENO, José Geraldo Silveira. As políticas de inclusão escolar: uma prerrogativa da educação especial? In __, J. G.S.; MENDES, G. L.;SANTOS, R. A, dos. (org.).

Deficiência e escolarização Novas perspectivas de analise. Araraquara: Junqueira e Marin, 2008.

BRASIL. Estatuto da Criança e do Adolescente no Brasil. Lei no 8.069, de 13 de julho de 1990. 
Diretrizes nacionais para a educação especial na educação básica. Brasília:

Ministério da Educação, SEESP, 2001.

Resolução n. 2, de 11 de setembro de 2001. Diretrizes para a Educação Especial na Educação Básica. Diário Oficial n. 177- Seção 1.

. Lei n ${ }^{\circ}$ 10.436. Dispõe sobre a Língua Brasileira de Sinais - Libras e dá outras providências. Publicada no Diário Oficial da União em 24/04/2002.

Decreto $n^{\circ}$ 5.626/2005. Regulamenta a Lei de $n^{\circ}$ 10.436, de 24 de abril de 2002, que dispõe sobre a Língua Brasileira de Sinais - Libras e o art. 18 da Lei $n^{\circ} 10.098$, de 19 de dezembro de 2000. Publicada no Diário Oficial da União em 22/12/2005.

. Política Nacional de Educação Especial na perspectiva da educação inclusiva. Brasília: Ministério da Educação, SEESP, 2008.

Secretaria de Direitos Humanos. Plano nacional dos direitos da pessoa com deficiência: viver sem limites. 2011. Disponível em:

<http://www.pessoacomdeficiencia.gov.br/app/sites/default/files/arquivos/\%5Bfield_gener icoimagens-filefield-description\%5D_0.pdf>. Acesso em: 15 fev. 2012.

.Lei no 13.005. Aprova o Plano Nacional de Educação - PNE e dá outras providências. Publicada no Diário Oficial da União em 25/06/2014.

CAMPOS, Mariana de Lima Isaac Leandro. Educação inclusiva para surdos e as políticas vigentes. In: LACERDA, Cristina Broglia Feitosa de; SANTOS, Lara Ferreira dos (Org.) Tenho um aluno surdo, e agora?: Introdução à LIBRAS e educação de surdos. São Carlos: EdUFSCar, 2013.

CERTEAU. Michel de. Teoria e Método no Estudo das Práticas Cotidianas. In: SZMRECSANYI, Maria Irene. (Org.). Cotidiano, Cultura Popular e Planejamento urbano. FAU/USP, São Paulo: 1985, p. 13 -19.

D’ ANTINO, Maria Eloisa Fama. A questão da integração do aluno com deficiência mental na escola regular. In: MANTOAN, Maria Teresa Eglér. (Org.). A integração de pessoas com deficiência. Contribuições para uma reflexão sobre o tema. São Paulo: SENAC, 1997.

DERMATINI. Zeila de Brito Fali. Culturas escolares: algumas questões para a História da Educação. In: GOMES, Antonio. (Org.). III Congresso Brasileiro de História da Educação. Sociedade Portuguesa de Ciências da Educação, Coimbra: 2004.

FILHO, Luciano Mendes de Faria. Escolarização, culturas, e práticas escolares no Brasil: elementos teóricos-metodológicos de um programa de pesquisa. In: LOPES, Alice Casimiro; MACEDO, Elisabeth. (Org.). Disciplina e integração curricular: histórias e políticas. Rio de Janeiro: DP\&A, 2002.

HARGREAVES, Andy. El cambio educativo: entre la inseguridad y la comunidad. In: Revista Propuesta Educativa. No 27. [s.d.], p. 63-69.

LODI, Ana Claudia Balieiro; MÉLO, Ana Dorziat Barbosade; FERNANDES, Eulália (Org.). Letramento, bilinguismo e educação de surdos. Porto Alegre: Mediação, 2012.

PATTO. Maria Helena Souza. Políticas atuais de inclusão escolar: reflexão a partir de um recorte conceitual. In BUENO, J. G. S.; MENDES, G. L.SANTOS, R. A, dos. (Org.).

Deficiência e escolarização Novas perspectivas de analise. Araraquara: Junqueira e Marin, 2008. 
PERLIN, Gladis; STROBEL, Karin. Fundamentos da educação de surdos. Florianópolis: UFSC, 2006. ISBN: 85-60522-02-6. Disponível em:

<http://www.libras.ufsc.br/hiperlab/avalibras/moodle/prelogin/adl/fb/logs/Arquivos/textos/ fundamentos/Fundamentos\%20da $\% 20$ Educa $\%$ E7\%E3o\%20de $\% 20$ Surdos_Texto-

Base.pdf>. Acesso em: 12/2014.

SILVA. Fabiany de Cássia Tavares. Desenhando a Cultura Escolar: ensino aprendizagem e deficiência mental nas salas de recursos e nas salas comuns. In J. G.S., MENDES; G. L.;SANTOS, R. A, dos. (org.). Deficiência e escolarização Novas perspectivas de analise. Araraquara: Junqueira e Marin, 2008.

SKLIAR, Carlos. A surdez: um olhar sobre as diferenças. Porto Alegre: Editora Mediação, 1998.

VIDAL, Diana Gonçalves. Culturas escolares: estudo sobre práticas de leitura e escrita na escola pública primária (Brasil e França, final do século XIX).São Paulo: Autores Associados, 2005. .; SCHWARTZ, Cleonara Maria. Sobre cultura escolar e história da educação.In: . História das Culturas Escolares no Brasil. Vitória: Edufes, 2010.

Recebido 15-04-2015

Aprovado 11/2016 